\title{
Use of Prescription Assistance Programs After the Affordable Health Care Act
}

\author{
Ghazala Khan, MD; Patrick Karabon, MS; and Sarah Lerchenfeldt, PharmD
}

\begin{abstract}
BACKGROUND: Insurance coverage in the United States seems to be in a state of unrest. The 2010 passage of the Patient Protection and Affordable Health Care Act (ACA) extended health insurance coverage to roughly 32 million people. An increase in the number of people with health insurance benefits raised the question of whether prescription assistance programs (PAPs) would still be used after ACA implementation.
\end{abstract}

OBJECTIVE: To evaluate the use of PAPs following the implementation of the ACA insurance mandate.

METHODS: Health insurance was not required by the ACA until January 2014, so we retrospectively examined the use of drug company-sponsored PAPs before and after the ACA implementation. Since each PAP had its own qualifying criteria, any person who used a PAP through the assistance of NeedyMeds and its PAPTracker between the years of 2011 and 2016 were included for analysis. Data were pulled by NeedyMeds from the PAPTracker software, which produces completed PAP applications from drug manufacturer forms for PAPs. The number of PAP orders, number of unique patient orders, and annual patient prescription savings were assessed.

RESULTS: Between 2011 and 2013, there was an average of 4.2 annual PAP orders per patient; however, annual PAP orders decreased to 3.1 per patient between 2014 and $2016(P<0.001)$. PAP orders declined by an average of $3.0 \%$ per month between 2014 and $2016(P<0.001)$, and average prescription savings per order increased from $\$ 870.40$ before the ACA to $\$ 1,086.40$ after ACA implementation $(P=0.0024)$. Patients saved an average of over $\$ 3,000$ on prescriptions annually with the use of PAPs after the ACA mandate.

CONCLUSIONS: Although health care reform is inevitable, our study showed that PAPs remain important to help cover prescription drug costs for eligible patients, even with invariable changes to health insurance, including a health insurance requirement. While the ACA may have been an important step forward in extending health insurance coverage to millions, PAPs are still used to help U.S. patients obtain their medications at no cost or very low cost. These programs will most likely remain relevant until other approaches are taken to help alleviate the effects of increasing drug prices in the United States.

J Manag Care Spec Pharm. 2018;24(3):247-51

Copyright $\odot 2018$, Academy of Managed Care Pharmacy. All rights reserved.

\section{What is already known about this subject}

Studies have shown that the inability to afford medications is a common reason among all age groups, especially older adults, for nonadherence to medication regimens.

Prescription assistance programs (PAPS) offer brand-name drugs at reduced or no cost to eligible patients with specific financial needs. The 2010 passage of the Patient Protection and Affordable Health Care Act (ACA) extended health insurance coverage to approximately 32 million people.

\section{What this study adds}

After the implementation of the ACA insurance mandate, PAP orders significantly declined by an average of 3.0\% per month.

The average prescription savings per order significantly increased after the ACA insurance mandate, in which patients saved over $\$ 3,000$ on prescriptions annually with the use of PAPs.

Despite the ACA insurance mandate, PAPs were still used to help U.S. patients obtain their medications at reduced or no cost.

$\mathrm{H}$ ealth insurance coverage and medication affordability are important factors for quality health care. ${ }^{1-3}$ High medication costs are often cited as a barrier to quality health care, which is problematic, since prescription drug prices in the United States are among the highest in the world. Higher drug prices translate into higher out-of-pocket costs, premiums, and deductibles for U.S. patients. ${ }^{4,5}$ Studies have shown that the inability to afford medications is a common reason among all ages, especially older adults, for nonadherence to medication regimens. ${ }^{3}$ More than $25 \%$ of U.S. patients have not filled a prescription or have reduced their prescribed dose because of high costs. ${ }^{6}$

Despite these problems, pharmaceutical costs in the United States continue to increase. ${ }^{4}$ In an effort to help combat high drug costs, the pharmaceutical industry developed prescription assistance programs (PAPs), which offer brand-name drugs at reduced or no cost. These programs are available for eligible patients with specific financial needs. ${ }^{6}$ Many PAPs provide 3- to 4-month supplies of brand-name medications free of charge for 1 year, with the option for renewal. ${ }^{3}$ They can be a major resource for improving the quality of health care for low-income patients. A systematic review that examined the 


\section{TABLE 1 Study Demographics}

\begin{tabular}{|c|c|}
\hline & Overall Cohort, \% \\
\hline \multicolumn{2}{|l|}{ Sex } \\
\hline Male & 36.7 \\
\hline Female & 52.7 \\
\hline Unknown & 10.5 \\
\hline \multicolumn{2}{|l|}{ Race } \\
\hline Black & 19.0 \\
\hline White & 35.4 \\
\hline Hispanic & 7.3 \\
\hline Other & 4.7 \\
\hline Unknown & 33.5 \\
\hline \multicolumn{2}{|l|}{ Disability } \\
\hline Disabled & 3.0 \\
\hline Nondisabled & 87.4 \\
\hline Unknown & 9.6 \\
\hline \multicolumn{2}{|l|}{ Veteran status } \\
\hline Veteran & 0.2 \\
\hline Nonveteran & 90.2 \\
\hline Unknown & 9.6 \\
\hline \multicolumn{2}{|l|}{ Citizenship } \\
\hline Citizen & 89.2 \\
\hline Noncitizen & 1.2 \\
\hline Unknown & 9.6 \\
\hline \multicolumn{2}{|l|}{ Marital status } \\
\hline Married & 28.0 \\
\hline Divorced & 5.5 \\
\hline Single & 28.8 \\
\hline Widowed & 3.1 \\
\hline Unknown & 34.8 \\
\hline \multicolumn{2}{|c|}{ Age categories, years } \\
\hline$<30$ & 6.0 \\
\hline $30-39$ & 8.2 \\
\hline $40-49$ & 14.5 \\
\hline $50-59$ & 29.0 \\
\hline $60-69$ & 30.9 \\
\hline $70-79$ & 8.6 \\
\hline $80+$ & 2.9 \\
\hline \multicolumn{2}{|c|}{ Household size (persons) } \\
\hline Mean $( \pm S D)$ & $1.8( \pm 0.1)$ \\
\hline \multicolumn{2}{|c|}{ Average household income, \$ } \\
\hline Mean $( \pm$ SD) & $12,271 \quad( \pm 1,733)$ \\
\hline \multicolumn{2}{|c|}{ Average medical expenses, $\$$} \\
\hline Mean $( \pm$ SD $)$ & $217( \pm 122)$ \\
\hline
\end{tabular}

evidence for PAPs, suggested that PAP enrollment assistance plus additional medication services, such as counseling, were associated with improved disease indicators for patients with chronic diseases. ${ }^{7}$ Another study showed that patients who received coordinated prescription assistance experienced a $51 \%$ reduction in the likelihood of visiting the emergency room or hospital. ${ }^{8}$
The 2010 passage of the Patient Protection and Affordable Health Care Act (ACA) extended health insurance coverage to approximately 32 million people. An increase in those with health insurance raised the question of whether PAPs would still be used. ${ }^{7}$ While PAPs provide an important resource for patients unable to afford their medications, their relevance after health care reform may be questionable. Despite improved insurance coverage, however, patients may still face high costs for prescription medications or have difficulty obtaining approval for needed medications. ${ }^{8}$ Because insurance coverage in the United States seems to be in a state of unrest, we hypothesized that despite the improvements in health insurance coverage, PAPs will continue to be used.

\section{Methods}

NeedyMeds is a national nonprofit information resource that helps patients locate PAPs. ${ }^{9}$ NeedyMeds collects data from PAPTracker, a web-based software that produces completed PAP applications for patients. All available programs listed by NeedyMeds are drug company-sponsored PAPs for brand-name pharmaceuticals. NeedyMeds does not provide information on any other type of PAP to patients, such as employer-sponsored PAPs. Anyone can use the programs available through PAPTracker as long requirements are met as specified by the pharmaceutical companies funding the PAPs. ${ }^{9}$ All necessary information about the specific programs is available online, although it is up to the patient to complete the applications, get the necessary signatures, and send the form to the program. ${ }^{9}$ The inclusion criteria for this particular study were any patients who used PAPs through the assistance of NeedyMeds and the PAPTracker between 2011 and 2016. The demographics of the patient population are shown in Table 1.

Although the ACA was signed into law in March 2010, the health insurance mandate began in January 2014. We retrospectively examined the use of drug company-sponsored PAPs before and after ACA implementation. Data were reviewed to examine if PAPs were still used following an improvement in insurance coverage as a result of the ACA insurance mandate. Data were evaluated, including monthly PAP orders, number of unique patients, and annual prescription savings. Data on insurance status or specific insurance plans for patients who used PAPs through NeedyMeds were not available for analysis.

The Oakland University Institutional Review Board (IRB) determined that this project did not meet the definition of human subject research under the purview of the IRB according to federal regulations, since it was a retrospective analysis of deidentified data.

\section{Statistical Methods}

Log-linear trend models were used to show the trend of monthly PAP orders. Trend models were generated using linear regressions with a logged dependent variable (PAP orders) and 


\section{FIGURE 1 Trends in Monthly PAP Orders}

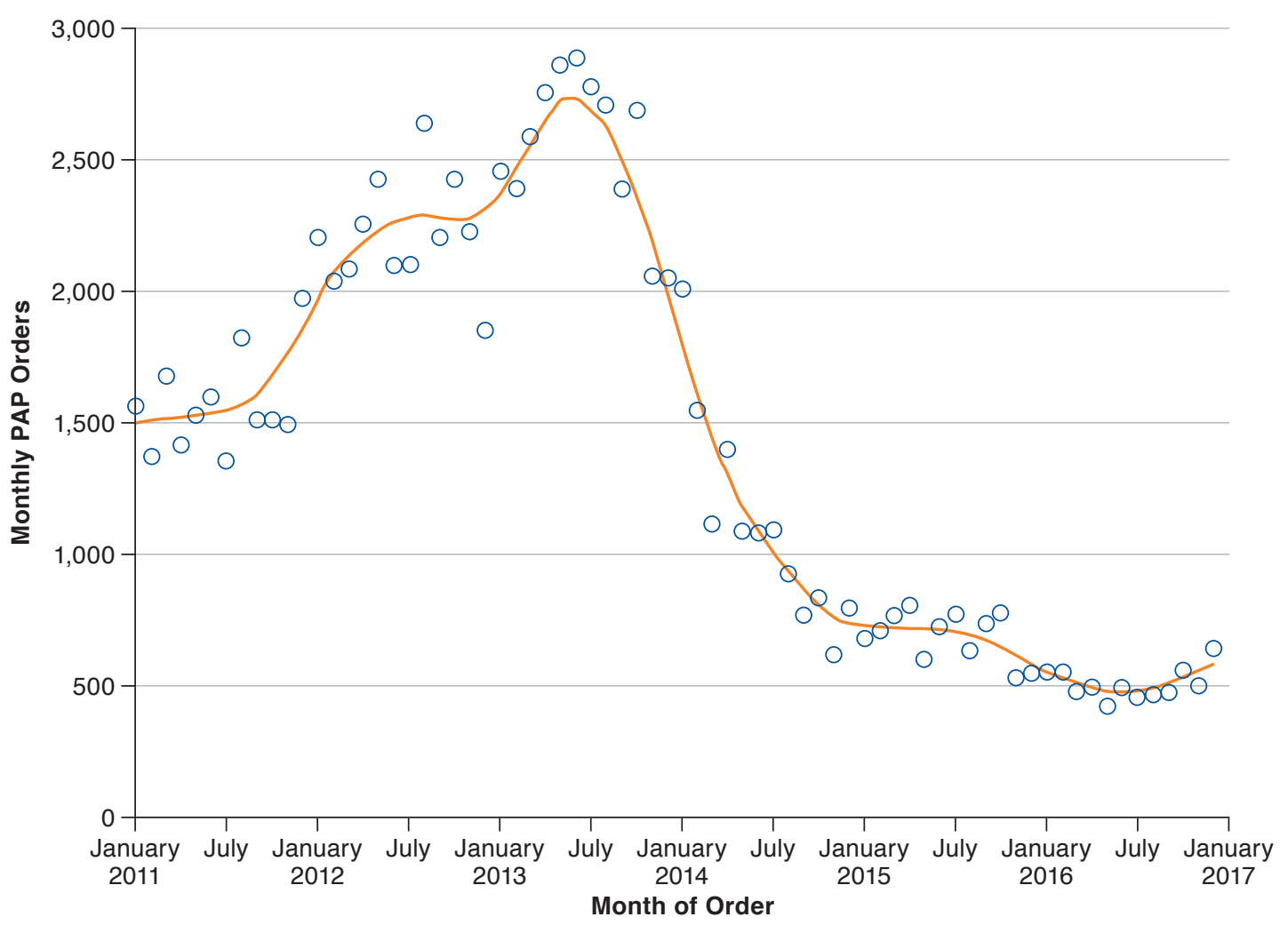

PAP $=$ prescription assistance program.

were interpreted as monthly average percentage changes in PAP orders. Seasonal adjustment of monthly PAP orders was not required because no seasonal trends were detected. The number of annual patient orders, as well as the average annual prescription savings per patient and prescription savings per order were compared before and after the ACA mandate using t-tests.

\section{Results}

PAPTracker data provided by NeedyMeds contained 15,482 unique patients who completed 103,588 PAP order applications between 2011 and 2016. There were 75,907 pre-ACA (20112013) PAP orders and 27,681 post-ACA (2014-2016) orders. Total prescription savings for the study period were $\$ 96.1 \mathrm{mil}$ lion, with $\$ 66.1$ million in pre-ACA savings and $\$ 30.1$ million in post-ACA savings. Average savings per PAP order were $\$ 928$. The average household income for PAP applicants through NeedyMeds was $\$ 12,000$.

\section{Trends Analysis for Monthly PAP Orders}

PAP orders declined by an average of 3.0\% per month between 2014 and 2016 ( $P \leq 0.0001$; Figure 1). More detailed yearly analysis shows that while PAP orders decreased by a monthly average of $8.0 \%$ in $2014(P<0.001)$, a further decline of $1.8 \%$ in 2015 was not significant $(P=0.0759)$ nor was a slight increase in the 2016 monthly average of $0.7 \%(P=0.456)$. Trend analysis that was run on each of the 20 most common prescriptions with PAP orders determined that declines were seen for every prescription, with average monthly decreases varying between $1.3 \%$ and $12.0 \%$ (all $P<0.05$ ).

\section{Analysis for Number of Annual Patient Orders}

Of the 15,482 unique patients, 3,268 patients (21.1\%) placed PAP orders before and after the mandate; 9,120 patients (58.9\%) placed orders before but not after the mandate; and 3,094 patients $(20.0 \%)$ placed orders after but not before the mandate. An average of 4.2 annual PAP orders per patient before the mandate decreased to 3.1 orders per patient after the mandate $(P<0.001)$.

\section{Analysis for Average Annual Patient Prescription Savings}

Before the mandate, the average annual prescription savings per patient was $\$ 3,637.10$, which declined to an average of 
$\$ 3,374.10$ after the mandate $(P=0.381)$. The average prescription savings per order increased from $\$ 870.40$ before the ACA to $\$ 1,086.40$ after ACA implementation $(P=0.002)$.

\section{Top Drugs Covered}

There are over 800 drugs listed by NeedyMeds that are covered through PAPs. The 10 most frequently covered drugs, with their percentage of total orders in parentheses, are as follows: Ventolin (3.54\%), Lipitor (3.51\%), Lantus (3.37\%), Advair (3.01\%), Nexium (2.87\%), Neurontin (2.49\%), Benicar (2.44\%), Accuretic (2.43\%), Norvasc (2.36\%), and Cymbalta (2.20\%).

\section{Discussion}

The ACA was implemented to improve the accessibility, affordability, and quality of health care in the United States. To many, it was considered the most important health care legislation enacted since the creation of Medicare and Medicaid in 1965. ${ }^{10}$ Since the ACA extended health insurance coverage to millions, it raised the question of whether PAPs would still be used. In order to assess the use of PAPs, our study examined the use of these programs in the midst of health care reform. We hypothesized that despite changes and potential improvements in health insurance coverage, PAPs would continue to be an important resource for many patients, since prescription use and costs are consistently on the rise.,.5

Interestingly, we found that PAP orders significantly declined after the ACA insurance mandate by an average of 3.0\% per month between 2014 and 2016, potentially showing that patient prescriptions were covered by the required insurance plan, so help from PAPs was not required as frequently. This decline in the number of PAP orders was seen throughout the 20 most frequently reported prescriptions. With that said, the most drastic decrease occurred in 2014, followed by a not significant decline in 2015. However, the number of PAP orders increased slightly in 2016. Although PAP orders declined after implementation of the ACA, there were still thousands of orders filled through the help of NeedyMeds each month. While the use of PAPs may have decreased once the health insurance requirement was implemented, there was still a clear demand for PAPs, since many orders were still placed to help patients obtain their medications.

When looking at patients who placed PAP orders, there was a statistically significant decrease in the average number of annual orders, from 4.2 per patient before the insurance mandate to 3.1 per patient after the mandate. Although statistically significant, it is not necessarily of practical significance. People seeking assistance, including low-income patients, completed about 3 PAP orders per year, showing there was still a potential need for prescription assistance. Since per patient annual orders has not dropped to zero, PAPs remain an important resource to help provide medications to U.S. patients at little or no cost.
Average annual prescription savings provided further proof that PAPs remain relevant. The average annual prescription savings per patient only decreased slightly, while the average prescription savings per order significantly increased after the ACA mandate. Patients still saved an average of over $\$ 3,000$ on prescriptions annually with the use of PAPs after the ACA mandate. According to the 2017 Federal Poverty Guidelines, the poverty guideline for 1 person is $\$ 12,060$, so a savings of $\$ 3,000$ is significant, considering that the average household income for PAP applicants from NeedyMeds was only $\$ 12,000 .^{11}$

Overall, the ACA expanded health insurance coverage, and the uninsured rate declined from $16.0 \%$ in 2010 to $9.1 \%$ in $2015 .^{10}$ Although the policies of the ACA have helped improve access to health care, many people continue to experience difficulties covering the costs of their medical expenses, including physician visits and prescription drugs. ${ }^{10}$ In 2012, more than 1 in 4 families experienced financial burdens of medical care, and families with incomes at or below $250 \%$ of the federal poverty level were more likely to experience financial burdens of medical care. ${ }^{12}$ According to Choudhry et al. (2009), prevalent use of PAPs highlights the inadequacy of public prescription drug coverage, especially since the financial eligibility criteria of many PAPs overlap with government programs such as Medicaid. ${ }^{6}$ Because of the potential financial burdens of medical care, PAPs may continue to assist those in need.

Prescription drug costs comprise a large part of the medical cost burden. Net spending on prescription drugs increased by about 20\% in the United States between 2013 and 2015. ${ }^{13}$ Use and cost of prescription drugs continue to increase-the growth in total retail prescription drug expenditures increased by $12.2 \%$ in 2014 , the largest increase since $2002 .{ }^{14}$ There was also a $1.8 \%$ increase in the number of retail prescriptions dispensed, which was primarily the result of ACA's enrollment expansion, in which the number of Medicaid prescriptions dispensed grew. ${ }^{14}$ Although the ACA has extended health insurance to millions, prescription affordability remains a problem, especially with the continued rise of prescription costs and use.

This study shows the relevance of PAPs despite increasing health insurance coverage through the ACA mandate. Although the ACA included additional cost control policies-specifically, substantial Medicaid rebates_rising drug costs remain a concern. ${ }^{10}$ Potential solutions include increased transparency in the production and development costs of manufacturers, increased Medicare and Medicaid beneficiary manufacturer rebates, and federal government authority to negotiate drug prices. $^{10,15}$ While these solutions may help address the high cost of prescription drugs, they will most likely not resolve all issues surrounding prescription drug costs and would also take time to plan and implement. It is also important to note that PAPs are not the perfect solution to combat high drug costs-they often do not cover medications such as cancer drugs, and filling out PAP forms can also effect clinic time and 
financial resources. ${ }^{16,17}$ Despite the insurance mandate, PAPs may continue to be a viable option for those unable to afford prescription medications.

\section{Limitations}

This study has several limitations. The study was retrospective with no control group. Data were limited, since we only reviewed data provided by the PapTracker from NeedyMeds, so the differences in PAP use and cost savings before and after the health insurance requirement may have been biased. We were also unable to control for any changes in drug prices or PAPs coverage during the 2011-2016 time frame. Future studies may focus on long-term trends in an ever-changing health policy landscape. This study did not analyze the true economic magnitude or clinical consequences of PAPs. As stated in the systematic review of the evidence for PAPs, a more thorough economic evaluation, including cost-effectiveness studies that compare PAP enrollment assistance programs to other medication access strategies would provide further understanding for the significance of PAPs. ${ }^{7}$

\section{Conclusions}

Health care reform is often a significant topic of debate in the United States. Although health care reform may produce many changes in our health care system, this study shows that PAPs continue to help cover prescription drug costs for eligible patients, even with invariable changes to health insurance, including a health insurance requirement. PAPs can play an important role in improving the quality of health care for many by providing access to medications that patients would otherwise not receive. While the ACA may have been an important step forward in extending health insurance coverage to millions, PAPs will most likely remain relevant until other approaches are taken to help alleviate the effects of increasing drug prices in the United States. Changes in health care policy may affect the relevance of PAPs in the future, although these programs will most likely provide help to those in need for years to come.

\section{Authors}

GHAZALA KHAN, MD, Department of Internal Medicine, St. Joseph Mercy Hospital, Ypsilanti, Michigan. PATRICK KARABON, MS, and SARAH LERCHENFELDT, PharmD, Department of Biomedical Sciences, Oakland University William Beaumont School of Medicine, Rochester, Michigan.

AUTHOR CORRESPONDENCE: Sarah Lerchenfeldt, PharmD, Department of Biomedical Sciences, Oakland University William Beaumont School of Medicine, O'Dowd Hall, Rm. 466, 586 Pioneer Dr., Rochester, MI 48309. Tel.: 248.370.3037;

E-mail: lerchenfeldt@oakland.edu.

\section{DISCLOSURES}

No outside funding supported this research. The authors have no relevant financial or nonfinancial relationships to disclose.

Study concept and design were contributed by Khan, Lerchenfeldt, and Karabon. Khan collected the data, and all authors participated in data analysis. The manuscript was primarily written by Lerchenfeldt, along with Khan and Karabon, and revised by Lerchenfeldt, along with Karabon and Khan.

\section{ACKNOWLEDGMENTS}

The authors thank NeedyMeds for allowing the use of data from its PAPTracker software. The authors are immensely grateful to Sam Landry from NeedyMeds who provided his time and insight throughout this project.

\section{REFERENCES}

1. Pisu M, Crenshaw K, Funkhouse E, et al. Medication assistance programs: do all in need benefit. Ethn Dis. 2010;20(4):339-45. Available at: https://www.ncbi.nlm. nih.gov/pmc/articles/PMC3854657/. Accessed February 2, 2018.

2. Ranji UR, Wyn R, Salganicoff A, Yu H. Role of health insurance coverage in women's access to prescription medicines. Women's Health Issues. 2007;17(6):360-66.

3. Shaw CR. Reducing the burden of medication costs to improve medication adherence. Nurse Pract. 2014;39(7):43-47. Available at: https://journals.lww. com/tnpj/fulltext/2014/07000/Reducing_the_burden_of_medication_costs_to_ improve.11.aspx. Accessed February 2, 2018.

4. American Association of Retired Persons. Why our drugs cost so much. May 2017. Available at: http://www.aarp.org/health/drugs-supplements/info2017/rx-prescription-drug-pricing.html. Accessed February 2, 2018.

5. Steinman MA, Sands LP, Covinsky KE. Self-restriction of medications due to cost in seniors without prescription coverage. J Gen Intern Med. 2001;16(12): 793-99. Available at: https://www.ncbi.nlm.nih.gov/pmc/articles/PMC1495305/. Accessed February 2, 2018.

6. Choudhry NK, Lee JL, Agnew-Blais J, Corcoran C, Shrank WH. Drug company-sponsored patient assistance programs: a viable safety net? Health Aff (Millwood). 2009;28(3):827-34. Available at: https://www.ncbi.nlm.nih.gov/pmc/ articles/PMC2873618/. Accessed February 2, 2018.

7. Felder TM, Palmer NR, Lai LS, Mullen PD. What is the evidence for pharmaceutical patient assistance? A systematic review. J Health Care Poor Underserved. 2011;22(1):24-49. Available at: https://www.ncbi.nlm.nih.gov/pmc/articles/ PMC3065996/. Accessed February 2, 2018.

8. Burley MH, Daratha KB, Tuttle K, et al. Connecting patients to prescription assistance programs: effects on emergency department and hospital utilization. J Manag Care Spec Pharm. 2016;22(4):381-87. Available at: https://www.jmcp.org/ doi/10.18553/jmcp.2016.22.4.381.

9. Sagall RJ. Pharmaceutical companies helping patients get their medicines. NeedyMeds.org. April 11, 2017. Available at: https://www.needymeds.org/pap. Accessed February 2, 2018.

10. Obama B. United States health care reform: progress to date and next steps. JAMA. 2016;316(5):525-32. Available at: http://jamanetwork.com/journals/jama/ fullarticle/2533698. Accessed February 2, 2018.

11. U.S. Department of Health and Human Services, Office of the Assistant Secretary for Planning and Evaluation. U.S. federal poverty guidelines used to determine financial eligibility for certain federal programs. January 31, 2017. Available at: https://aspe.hhs.gov/2017-poverty-guidelines. Accessed February 8, 2018.

12. Cohen RA, Kirzinger WK. Financial burden of medical care: a family perspective. NCHS Data Brief. 2014;(142):1-8. Available at: https://www.cdc.gov/ nchs/data/databriefs/db142.pdf. Accessed February 2, 2018.

13. Kesselheim AS, Avorn J, Sarpatwari A. The high cost of prescription drugs in the United States: origins and prospects of reform. JAMA. 2016;316(8):858-71 14. Martin AB, Hartman M, Benson J, et al. National health spending in 2014 faster growth drive by coverage expansion and prescription drug spending. Health Aff (Millwood). 2016;35(1):150-60.

15. Office of Management and Budget. Budget of the U.S. government. Fiscal year 2017. February 9, 2016. U.S. Government Publishing Office. Washington, DC. Available at: https://www.gpo.gov/fdsys/pkg/BUDGET-2017-BUD/pdf/BUDGET2017-BUD.pdf. Accessed February 2, 2018.

16. Zullig LL, Wolf S, Vlastelica L, Shankaran V, Zafar SY. The role of patient financial assistance programs in reducing costs for cancer patients. J Manag Care Spec Pharm. 2017;23(4):407-11. Available at: https://www.jmcp.org/doi/10.18553/ jmcp.2017.23.4.407.

17. Clay P, Vaught E, Giaros A, Mangum S, Hansen D, Lindsey CC. Costs to physician offices of providing medications via pharmaceutical manufacturer prescription assistance programs. J Manag Care Pharm. 2007;13(6):506-14. Available at: https://www.jmcp.org/doi/10.18553/jmcp.2007.13.6.506. 